\title{
Cell-free DNA Testing in Routine Practice: Characterisation of a Cohort with Positive Results for Trisomies, Sex Chromosome Anomalies and Microdeletions
}

\section{Zellfreie DNA-Tests im klinischen Alltag: Charakteristika einer Kohorte mit positiven Ergebnissen für Trisomien, Anomalien der Geschlechtschromosomen und Mikrodeletionen}

(c) (P) $\Theta$

Author

Ismail Tekesin

Affiliation

Prenatal Unit Stuttgart, Stuttgart, Germany

Key words

cell-free fetal DNA, NIPT, positive predictive value,

routine practice, ultrasound, anomaly scan

Schlüsselwörter

zellfreie fötale DNA, NIPT, positiver Vorhersagewert, klinischer Alltag, Ultraschall, Fehlbildungens-Ultraschall

$\begin{array}{ll}\text { received } & 25.5 .2020 \\ \text { accepted after revision } & 20.7 .2020 \\ \text { published online } & 24.11 .2020\end{array}$

Bibliography

Geburtsh Frauenheilk 2021; 81: 81-89

DOI 10.1055/a-1226-6538

ISSN 0016-5751

(c) 2020. The Author(s).

This is an open access article published by Thieme under the terms of the Creative Commons Attribution-NonDerivative-NonCommercial-License, permitting copying and reproduction so long as the original work is given appropriate credit. Contents may not be used for commercial purposes, or adapted, remixed, transformed or built upon. (https://creativecommons.org/licenses/by-nc-nd/4.0/)

Georg Thieme Verlag KG, Rüdigerstraße 14,

70469 Stuttgart, Germany

Correspondence

PD Dr. Ismail Tekesin

Prenatal Unit Stuttgart

Alte Poststraße 3, 70173 Stuttgart, Germany

tekesin@praenatalstuttgart.de

\section{ABSTRACT}

Introduction Cell-free DNA (cfDNA) testing is increasingly used as a screening method not only for trisomy ( $T$ ) 21 but also for T18 and T13, sex chromosome anomalies (SCA) and microdeletions. Based on cases with a positive cfDNA result in our specialised prenatal practice, this study aims to characterise the usage of cfDNA testing and to estimate the positive predictive value (PPV) in routine practice in Germany.

Patients and Methods In this retrospective study we analysed the data of all pregnant women with a positive cfDNA result seen between 09/2013 and 12/2019. Women were either referred due to the positive result or the test was initiated in our practice. The primary parameter of interest was the concordance of cfDNA tests with confirmatory genetic testing.

Results We encountered 81 cases with a positive cfDNA test (T21: 49.4\%; T18: 9.9\%; T13: 8.6\%; SCA: 22.2\%; 22q12del: $8.6 \%)$. The PPV was $95.0 \%$ for T21, but considerably lower for T18 (55.6\%) and T13 (28.6\%). For SCAs it was $23.1 \%$ and no case with DiGeorge syndrome was confirmed. $63 \%$ of the patients had not received a fetal anomaly scan before cfDNA testing. In first-trimester fetuses with a cfDNA test predicting an autosomal aneuploidy, fetal anomalies were detected in $90.3 \%$ of the cases. No false positive case had an abnormal US result.

Conclusions Despite the excellent specificity of cfDNA tests, the PPV for aneuploidies other than T21 is low in routine practice. In discordance with the current guidelines, cfDNA test is often used without a previous detailed anomaly scan. Our data provide valuable information to assist patient counselling and shared decision making.

\section{ZUSAMMENFASSUNG}

Einleitung Zellfreie DNA-Tests (cfDNA) werden immer häufiger als Untersuchungsmethode eingesetzt, nicht nur zur Identifizierung von Trisomie ( $T$ ) 21, sondern auch zur Erkennung von T18 und T13 sowie zur Aufdeckung von Anomalien der Geschlechtschromosomen (SCA) und von Mikrodeletionen. Basierend auf den Fällen mit positiven cfDNA-Ergebnissen aus unserer spezialisierten Pränatalpraxis, will diese Studie 
den Einsatz von cfDNA-Tests beschreiben und den Nutzen eines positiven Vorhersagewerts (PVW) im klinischen Alltag in Deutschland evaluieren.

Patientinnen und Methoden In dieser retrospektiven Studie wurden die Daten aller Schwangeren mit einem positiven cfDNA-Testergebnis, die zwischen 09/2013 und 12/2019 in unserere Praxis vorstellig wurden, analysiert. Entweder wurden die Frauen wegen eines positiven Testergebnisses an uns überwiesen oder der Test wurde in unserer Praxis durchgeführt. Der vorrangige Parameter von Interesse war die Höhe der Übereinstimmung zwischen den Ergebnissen der cfDNA-Tests und den genetischen Tests, die zur Bestätigung durchgeführt wurden.

Ergebnisse Insgesamt gab es 81 Fälle mit einem positiven cfDNA-Test (T21: 49,4\%; T18: 9,9\%; T13: 8,6\%; SCA: 22,2\%; 22q12del: 8,6\%). Der PVW für T21 betrug 95,0\%, aber der jeweilige PVW für T18 (55,6\%) und für T13 (28,6\%) war erheb- lich niedriger. Der PVW für SCAs betrug 23.1\%, und es ließ sich kein Fall mit DiGeorge-Syndrom bestätigen. 63\% der Patientinnen hatten vor dem cfDNA-Test keine Ultraschalluntersuchung auf fetale Anomalien bekommen. Bei Feten im 1. Schwangerschaftstrimester und einem cfDNA-Test, der auf eine autosomale Aneuploidie hinweis, wurden in 90,3\% der Fälle eine fetale Anomalie entdeckt. Kein Fall mit einem falsch positiven Ergebnis hatte einen auffälligen Ultraschall.

Schlussfolgerungen Obwohl die Spezifität von cfDNA-Tests sehr hoch ist, ist der PVW für Aneuploidien in der klinischen Praxis mit Ausnahme von T21 recht niedrig. Entgegen den aktuellen Richtlinien werden cfDNA-Tests oft eingesetzt, ohne dass vorher eine sorgfältige Ultraschalluntersuchung auf Anomalien durchgeführt wird. Unsere Daten liefern wertvolle Informationen, die bei der Patientinnenberatung und der gemeinsamen Entscheidungsfindung eingesetzt werden können.

\section{Introduction}

Testing of cell-free DNA (cfDNA), which mainly derives from apoptotic cells of the trophoblast, has been increasingly adopted into prenatal care during the past decade. A current meta-analysis confirms an excellent test performance in the detection of trisomy 21 (T21) with a sensitivity of up to $99.7 \%$ and a low false positive rate of $0.04 \%$ [1]. The accuracy for trisomy 18 (T18) and trisomy 13 (T13) seems only marginally lower [1,2]. However, due to the high costs, it has not been deemed suitable as a first-line screening method and the question as to how it can be best integrated into medical care is still under debate.

The current international guidelines recommend cfDNA testing for the trisomies T21/18/13 in combination with a qualified ultrasound (US) examination and stress the importance of adequate patient education and counselling [3,4]. Although the providers of cfDNA-screening tests offer screening for sex chromosome anomalies (SCAs) and microdeletion syndromes (especially microdeletion 22q11.2) the test performance is clearly lower and data on validity is scarce. Thus, testing for SCAs or microdeletions via cfDNA is not advised $[3,4]$.

In Germany, there is generally no reimbursement neither for conventional first-trimester screening nor cfDNA testing. Only recently (09/2019) the authorities decided on limited coverage for cfDNA testing in individual cases with a high risk for T21, 18 and 13. However, since cfDNA testing allows virtually risk-free screening at an early stage of pregnancy and involves only a simple blood draw for the patient, many parents are willing to meet the costs themselves. Since cfDNA testing is a genetic examination, it is all the more important that the parents are well informed and properly counselled about the test performance of cfDNA testing, its advantages and limitations and potential interpretation of its results.

Whereas initially the accuracy of cfDNA testing was determined in high-risk populations, it is increasingly used also in populations with a low risk for aneuploidies. Large studies on the performance of cfDNA tests in clinical routine report a consistently high specificity and sensitivity [5]. However, several reports demonstrate that the actual positive predictive value (PPV) in clinical routine is lower than expected and describe a relevant proportion of false positive cfDNA test results [6-8]. Reasons such as confined placental or true fetal mosaicism and technical or human errors were identified as reasons for cfDNA test results that are discordant with the true fetal karyotype [9]. Thus, more data from routine practice is required to improve counselling of parents and enable informed decision-making, especially if it is taken into consideration that false positive or negative results may have farreaching consequences such as unnecessary or late terminations, respectively.

During recent years we observed a considerable number of patients with a positive cfDNA test result in our referral centre for specialised prenatal care. With a structured workup of these cases we aim to describe how cfDNA-testing is applied and to provide PPV estimates in a routine setting in Germany.

\section{Methods}

\section{Study design}

This is a retrospective study including all patients with a positive cfDNA test result that were encountered in our unit specialising in prenatal diagnosis between September 2013 and December 2019. Patients are usually referred to our practice in southern Germany by their regional primary gynaecologist for specialised diagnostics and further counselling. Referral indications include suspicious clinical findings (e.g. positive cfDNA test, anomalies detected in routine US scans), high-risk pregnancies or the patient's own request.

\section{Parameters}

The PPVs of cfDNA tests for autosomal aneuploidies (T21, T18, $\mathrm{T} 13)$, sex chromosome aneuploidies (X0, XXX, XXY, XYY) or a $22 q 11.2$ microdeletion (DiGeorge syndrome) were defined as the ratio of true positive cases divided by all patients with a positive 
test result for the respective anomaly. Confirmatory genetic testing (pre- or postnatally) was used as a reference standard.

Pregnancy outcomes were "delivered", "intrauterine death" (IUD) and "termination of pregnancy" (TOP).

To describe the current utilisation of cfDNA testing in clinical practice, the following parameters were assessed: maternal characteristics, gestational age (GA) at cfDNA test, ultrasound (US) examination or first trimester screening (FTS) before cfDNA test, presence of fetal anomalies, indication for cfDNA test, invasive prenatal testing method. A cfDNA test was defined as a "screening cfDNA test" if either no US/FTS was performed before blood sampling or if a US/FTS before blood sampling yielded normal results.

Parameters were described in the total population and in groups with a cfDNA test positive for autosomal aneuploidies, SCAs or 22q11.2 microdeletion.

\section{Data and measurements}

In our practice, all patients routinely receive a detailed 2D US scan at their first visit. Maternal demographic characteristics, clinical findings and pregnancy outcome are recorded in a database.

At a CRL $\geq 45$ and $\leq 84 \mathrm{~mm}$, a detailed first trimester US examination including measurement of fetal NT thickness, assessment of the additional ultrasound markers nasal bone (NB), flow in the ductus venosus (DV) and across the tricuspid valve (TV) was performed. Additionally, a thorough anatomical assessment was carried out to detect any fetal defects. At a CRL $>84 \mathrm{~mm}$, a detailed fetal anomaly scan was performed. All US examinations followed the current guidelines [10-13]. A single operator using a 2- to 6Mhz multifrequency transabdominal probe (Voluson E8, GE Medical Systems, Zipf, Austria) conducted all measurements. A transvaginal probe (6- to 12-MHz multifrequency) was used when the fetus was at risk of a cardiac anomaly or in order to complete the anatomical survey when the scanning quality was not acceptable transabdominally. The examiner was certified for evaluation of the ultrasound markers by the Fetal Medicine Foundation (FMF), UK.

In our practice FTS was based on MA, NT thickness and the additional US markers DV and TV. The risk was calculated according to the algorithm of the FMF 2012 with the program ViewPoint (GE healthcare, Chicago, Illinois, USA). Pregnancies with a risk for T21 $\geq 1$ : 50 were classified as "high-risk FTS". FTS by the primary gynaecologists was usually based on MA, NT thickness and maternal levels of serum free $\beta$-human chorionic gonadotropin ( $\beta$-hCG) and pregnancy-associated plasma protein A (PAPP-A).

Invasive prenatal testing (IPT) was offered to all patients with a positive cfDNA test following the detailed US examination [14, 15]. The samples were sent for karyotyping to the Genetikum ${ }^{\circledR}$ Stuttgart.

For this study, we collected the required data from our database and (if necessary) retrieved information on GA at blood sampling for cfDNA test, the cfDNA test provider, previous results from US examinations or FTS, pregnancy outcome and results of postnatal genetic testing from the patients' primary gynaecologist, the patients or the Genetikum Stuttgart (with the patients' consent). The cfDNA tests used were the Harmony ${ }^{\circledR}$ prenatal test (Roche Inc., San Jose, CA, USA), the PrenaTest ${ }^{\circledR}$ (Eurofins Life- codexx AG, Konstanz, Germany) and the PreviaTest ${ }^{\circledR}$ (Eluthia GmbH, Gießen, Germany).

\section{Statistics}

For the calculation of the true and false positive rates, only patients with a confirmatory genetic testing result were included in the analysis. The 95-\%-confidence intervals were calculated according to Pearson-Clopper. Data analysis was carried out using SAS version 9.3.

\section{Ethics}

All procedures performed in this study were in accordance with the ethical standards of the 1964 Helsinki Declaration and its later amendments. The patients gave their general consent to anonymised data handling before their examinations. As this is a retrospective analysis of data derived from a routine clinical examination, the approval of the Ethics Committee was not required.

\section{Results}

\section{Patient population}

From 09/2013 to 12/2019 we encountered 81 patients with a positive cfDNA test result in our specialised prenatal practice. Most women ( $n=71,87.7 \%$ ) were referred to our practice due to the positive cfDNA test result. In 10 cases (12.3\%), the cfDNA test was initiated in our practice. The median maternal age of the total study population $(n=81)$ was 37 (range: $27-44)$ years and the median GA at the first examination at our practice was 13.6 (range: 11.6-26.6) weeks. All pregnancies were singleton pregnancies. Five (5.2\%) fetuses were conceived by in vitro fertilisation (IVF). - Fig. 1 provides an overview over the results of cfDNA testing, confirmatory genetic testing and the pregnancy outcomes of the study population.

\section{Test results and utilisation of cfDNA testing}

The most frequent positive cfDNA test result was T21 $(n=40$; 49.4\%), followed by T18 ( $n=8 ; 9.9 \%)$ and T13 ( $n=7 ; 8.6 \%)$. In 18 cases $(22.2 \%)$, the cfDNA test predicted a SCA (X0: $n=6$ [7.4\%], XXX: $n=6$ [7.4\%], XXY: $n=5$ [6.2\%]; XYY: $n=1$ [1.2\%]). One patient had a double positive cfDNA test for T18 and triple $X$ syndrome. Seven patients (8.6\%) had a positive cfDNA test for a 22q11.2 deletion.

Blood sampling for cfDNA testing mainly took place in the first trimester of pregnancy (88.9\%) and $70.4 \%$ of the pregnant women were $\geq 35$ years old.

In $85.2 \%$ of the cases, cfDNA testing was used as a screening method, i.e. before blood sampling no US or FTS had been performed or it had yielded a normal result. Only $11.1 \%$ of the cfDNA test were initiated due to an abnormal US result, whereas $63.0 \%$ of the patients had not received a first-trimester anomaly scan before. - Table 1 describes the characteristics of the positive cfDNA test cases stratified for autosomal aneuploidies, SCAs and 22q11.2 deletion.

In the total population, the median percentage of fetal cfDNA was $8.7 \%$ and in all cases, it was above the threshold of $4 \%$ (range: 4.3-23.4\%). The blood samples were mainly sent to the local 


\section{Patients with a positive cf-DNA test: $\mathbf{n}=\mathbf{8 1}$}

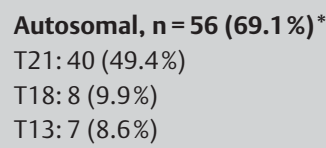

SCA, $\mathbf{n}=19(23.5 \%)^{*}$

$X 0: \quad 6(7.4 \%)$

$X X X: 6(7.4 \%)$

$X X Y: 5(6.2 \%)$

$X Y Y: 1(1.2 \%)$
Microdeletion, $\mathrm{n}=\mathbf{7}(\mathbf{8 . 6 \% )}$

DiGeorge syndrome: 7 (8.6\%)

\section{T18 and Triple $\mathrm{X}: \mathrm{n}=1(1.2 \%)$}

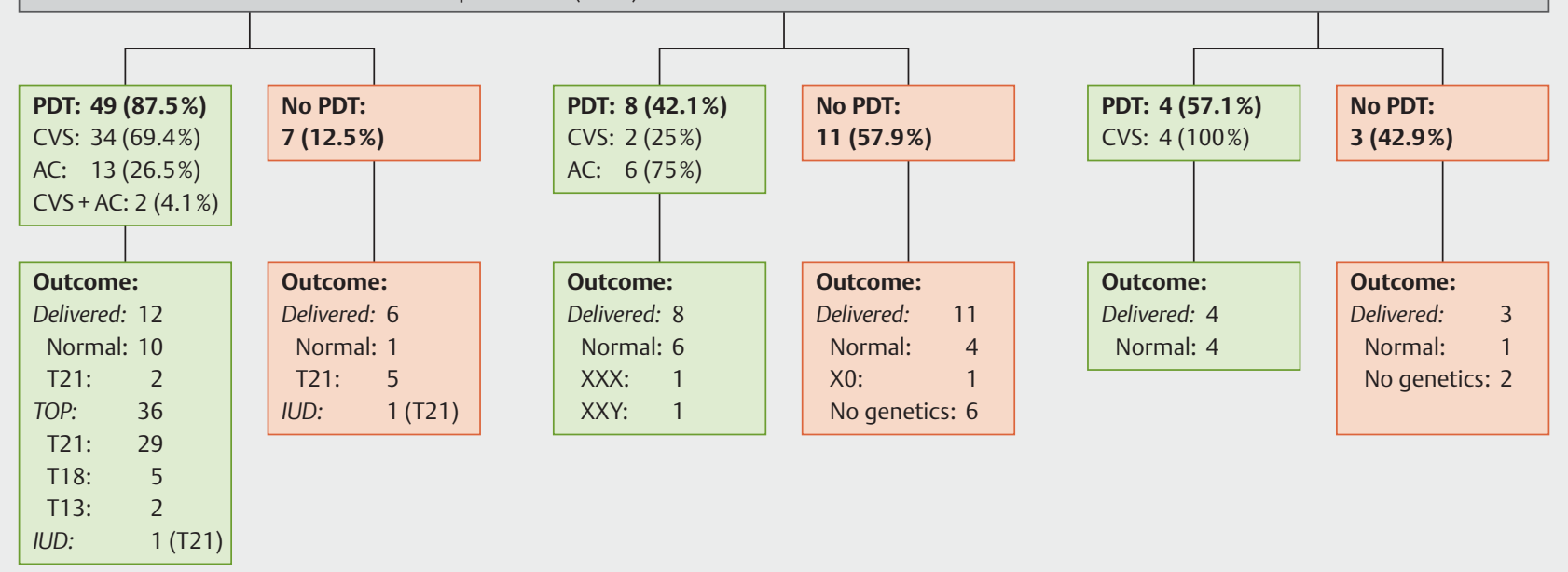

- Fig. 1 Flow chart depicting patient flow, results of confirmatory testing results and outcomes. AC: amniocentesis; cfDNA: cell free DNA; CVS: chorionic villus sampling; IUD: intrauterine death; IPT: invasive prenatal testing; SCA: sex chromosome aneuploidy; TOP: termination of pregnancy; T: trisomy. ${ }^{*}$ including the fetus with a double positive cfDNA result (T18 and triple $\mathrm{X}$ syndrome).

cfDNA test provider Cenata GmbH (Tübingen, Germany) using the Harmony prenatal test $(n=72 ; 88.9 \%)$. Eight patients $(9.9 \%)$ chose the PrenaTest and one (1.2\%) the PreviaTest.

\section{Performance of cfDNA testing in routine practice}

To assess the performance of cfDNA testing in routine practice, only the 73 fetuses ( 74 positive cfDNA test results) with a confirmatory genetic testing (pre- or postnatally) were included in the analysis.

In 26 out of 74 cases (35.1\%) the positive cfDNA test result was discordant with the diagnostic cytogenetic testing result ( $\triangleright$ Table 2). cfDNA testing for T21 yielded the highest predictive value: 38 out of 40 cases with a positive cfDNA test for T21 were confirmed, yielding a PPV of $95.0 \%$. However, for T18 and T13 the PPV was only $55.6 \%$ (T18) and $28.6 \%$ (T13), respectively. Only $23.1 \%$ of the predicted SCAs were confirmed and no fetus was diagnosed with DiGeorge syndrome ( $\triangleright$ Table 2 ).

\section{Structured workup of cases}

For a structured workup, we divided the population into four groups based on the cfDNA test result:

1. autosomal aneuploidy,

2. double positive test,

3. SCA and

4. 22q11.2 deletion.

\section{Cases with a positive cfDNA test for an autosomal} aneuploidy

Fifty-five fetuses had a positive cfDNA test result for an autosomal aneuploidy. Since our US examination routine differs in the first and second trimester of pregnancy, we further separated the group in fetuses that had a CRL $\geq 45$ and $\leq 84 \mathrm{~mm}(\mathrm{n}=38)$ and those with a CRL $>84 \mathrm{~mm}(\mathrm{n}=17)$ at the first visit in our practice (which could be before or after the cfDNA test).

First visit in first trimester: 38 (69.1\%) fetuses had a CRL $\geq 45$ and $\leq 84 \mathrm{~mm}$ at the first visit in our practice and thus received a detailed first trimester ultrasound examination including measurement of NT and the additional markers NB, DV, TV as well as a thorough anatomical assessment.

Thirty women had an increased risk for an autosomal aneuploidy based on US/FTS results: in 28 fetuses, we detected an US anomaly ( $\triangleright$ Table 3 ) and 2 cases had a high-risk FTS due to abnormal biochemical markers only. Of those, 27 women opted for invasive prenatal testing ( 25 CVS, 2 AC). In all these cases, the cfDNA test results were confirmed by karyotyping (T21: $n=25$; T18: $n=3$; T13: $n=2$ ). 25 pregnancies were terminated, one IUD occurred (T21) and one child with T21 was delivered. Three women that had fetuses displaying an enlarged NT, nasal bone hypoplasia and other US anomalies did not undergo IPT. One fetus with a screening cfDNA test positive for T21 died spontaneously in utero. In the other two cases, the expectant parents had first obtained the US result indicating a high risk for T21 and chose the 
- Table 1 Utilisation of cfDNA-testing.

\begin{tabular}{|c|c|c|c|c|c|c|}
\hline & $\begin{array}{l}\text { All } \\
n=81\end{array}$ & $\begin{array}{l}\text { T21 } \\
n=40\end{array}$ & $\begin{array}{l}\mathrm{T} 18^{*} \\
\mathrm{n}=9\end{array}$ & $\begin{array}{l}T 13 \\
n=7\end{array}$ & $\begin{array}{l}\text { SCA* } \\
n=19\end{array}$ & $\begin{array}{l}22 q 12.2 \\
n=7\end{array}$ \\
\hline \multicolumn{7}{|l|}{ Maternal age } \\
\hline . $<35$ years, $\mathrm{n}(\%)$ & $24(29.6)$ & $10(25.0)$ & $3(33.3)$ & $3(42.9)$ & $7(36.8)$ & $2(28.6)$ \\
\hline - $\geq 35$ years, $n(\%)$ & $57(70.4)$ & $30(75.0)$ & $6(66.7)$ & $4(57.1)$ & $12(63.2)$ & $5(71.4)$ \\
\hline \multicolumn{7}{|l|}{ Median GA at cfDNA test** } \\
\hline - week + days (range) & $\begin{array}{l}12+3 \\
(10+1-27+4)\end{array}$ & $\begin{array}{l}12+3 \\
(10+1-27+4)\end{array}$ & $\begin{array}{l}12+4 \\
(10+1-21+6)\end{array}$ & $\begin{array}{l}12+4 \\
(11+0-13+0)\end{array}$ & $\begin{array}{l}12+2 \\
(10+1-13+5)\end{array}$ & $\begin{array}{l}12+4 \\
(12+1-13+0)\end{array}$ \\
\hline - cfDNA at GA $\leq 13.6, \mathrm{n}(\%)$ & $72(88.9)$ & $33(82.5)$ & $7(77.8)$ & $7(100.0)$ & $19(100.0)$ & $7(100.0)$ \\
\hline - cfDNA at $G A \geq 14.0, n(\%)$ & $9(11.1)$ & $7(17.5)$ & $2(22.2)$ & 0 & 0 & 0 \\
\hline Screening cfDNA test ${ }^{\#}$ & $69(85.2 \%)$ & $30(75.0)$ & $8(88.9)$ & $6(85.7)$ & $19(100.0)$ & $7(100.0)$ \\
\hline \multicolumn{7}{|c|}{ Fetal anomaly scan before cfDNA testing } \\
\hline - no, n (\%) & $51(63.0)$ & $26(65.0)$ & $7(77.8)$ & $5(71.4)$ & $11(57.9)$ & $3(42.9)$ \\
\hline - yes, normal, n (\%) & $20(24.7)$ & $7(17.5)$ & $1(11.1)$ & $1(14.3)$ & $8(42.1)$ & $4(57.1)$ \\
\hline " yes, abnormal, n (\%) & $9(11.1)$ & $7(17.5)$ & $1(11.1)$ & $3(42.9)$ & 0 & 0 \\
\hline \multicolumn{7}{|l|}{ FTS before cfDNA testing } \\
\hline - no, n (\%) & $62(76.5)$ & $29(72.5)$ & $7(77.8)$ & $5(71.4)$ & $15(78.9)$ & $7(100.0)$ \\
\hline - yes, normal, n (\%) & $13(16.1)$ & $6(15.0)$ & $2(22.2)$ & $1(14.3)$ & $4(21.1)$ & 0 \\
\hline " yes, suspicious, n (\%) & $6(7.4)$ & $5(12.5)$ & 0 & $1(14.3)$ & 0 & 0 \\
\hline \multicolumn{7}{|l|}{ cfDNA testing performed at } \\
\hline - external practice & $71(87.7)$ & $37(92.5)$ & $7(77.8)$ & $6(85.7)$ & $15(78.9)$ & $7(100.0)$ \\
\hline - our practice & $10(12.3)$ & $3(7.5)$ & $2(22.2)$ & $1(14.3)$ & $4(21.1)$ & 0 \\
\hline \multicolumn{7}{|l|}{ Invasive prenatal testing } \\
\hline . CVS & $40(49.4)$ & $28(70.0)$ & $5(55.6)$ & $2(28.6)$ & $2(10.5)$ & $4(57.1)$ \\
\hline$=A C$ & $18(22.2)$ & $5(12.5)$ & $3(33.3)$ & $4(57.1)$ & $6(31.6)$ & 0 \\
\hline - CVS and AC & $2(2.5)$ & $1(2.5)$ & $1(1.1)$ & 0 & 0 & 0 \\
\hline - no & $21(25.9)$ & $6(15.0)$ & 0 & $1(14.3)$ & $11(57.9)$ & $3(42.9)$ \\
\hline $\begin{array}{l}\text { * including the fetus with a } \\
{ }^{* *} \text { GA at blood sampling for } \\
\text { \# cfDNA test was classified } \\
\text { AC: amniocentesis; cfDNA: ce }\end{array}$ & $\begin{array}{l}\text { Jble positive cfDI } \\
\text { NA test } \\
\text { screening cfDNA } \\
\text { ree fetal DNA; CV }\end{array}$ & $\begin{array}{l}\text { est result (T18 an } \\
\text { " if no US/FTS wa } \\
\text { orionic villus san }\end{array}$ & $\begin{array}{l}\text { le X syndrome) } \\
\text { formed before b } \\
\text { g; GA: gestation }\end{array}$ & $\begin{array}{l}\text { sampling or a US } \\
\text { e; FTS: first trime }\end{array}$ & $\begin{array}{l}\text { before blood sa } \\
\text { screening }\end{array}$ & ng was normal. \\
\hline
\end{tabular}

cfDNA test instead of IPT for confirmation. Both children with T21 were delivered.

There were 8 first-trimester fetuses with a positive test result for an autosomal aneuploidy which did not detect an US anomaly (T21: $n=1, T 18: n=3, T 13: n=4)$. Seven women opted for IPT (CVS: $n=2 ; A C: n=4$; both: $n=1$ ). One fetus was confirmed to have T18 following AC and the pregnancy was terminated. In the other 6 cases, the cfDNA test result turned out to be false positive. Among those, there was one case with placental trisomy 18 mosaicism detected by long-term CVS culture. Karyotyping following $A C$ in week $17+0$ affirmed euploidy.

A 31-year-old patient referred for counselling due to a positive cfDNA test for T13 (GA $11+1$ weeks) decided against IPT, since no anomalies were detected at the detailed first trimester scan at a $\mathrm{GA} 13+4$. A healthy child was delivered.

Taken together, in the group without anomalies in first trimester US examination (or no high-risk FTS) all but one of the cases with a positive cfDNA test were discordant with the genetic result.
One case with T18 that was otherwise unsuspicious was identified.

First visit in second trimester: 17 (30.9\%) pregnancies with a cfDNA test positive for an autosomal aneuploidy were already in the second or third trimester at the first visit in our practice and received a thorough anatomical assessment only. Fetal anomalies were detected in 12 fetuses ( $\triangleright$ Table 3 ). Among those were 8 women who had a screening cfDNA test predicting T21 and were referred to our practice for IPT. T21 was confirmed in all cases (CVS: $n=5$; AC: $n=2$; both: $n=1$ ) and the pregnancies were terminated.

A 35-year-old woman was referred for detailed second trimester US screening at a GA $21+6$. We identified a heart anomaly and initiated cfDNA test, which resulted in T18 ( $\vee$ Table 3 ). The couple opted for AC in week $26+2$. T18 was confirmed and the pregnancy was terminated.

There were 3 cases with typical ultrasound anomalies pointing towards a high risk for T21 that were detected in the second tri- 
- Table 2 Prediction values of cfDNA testing.

\begin{tabular}{|c|c|c|c|c|c|}
\hline & $\begin{array}{l}\text { cfDNA test } \\
\text { positive, } n\end{array}$ & $\begin{array}{l}\text { Diagnostic testing } \\
\text { positive, } n\end{array}$ & $\begin{array}{l}\text { Diagnostic testing } \\
\text { negative, } n\end{array}$ & PPV, \% (95\% Cl) & FPR, \% (95\% Cl) \\
\hline Trisomy 21 & 40 & 38 & 2 & $95.0(83.1-99.4)$ & $5.0(0.1-16.9)$ \\
\hline Trisomy 18 & $9^{*}$ & 5 & 4 & $55.6(21.2-86.3)$ & $44.4(13.7-78.8)$ \\
\hline Trisomy 13 & 7 & 2 & 5 & $28.6(3.7-71.0)$ & $71.4(29.0-96.3)$ \\
\hline SCA & $13^{*}$ & 3 & 10 & $23.1(5.5-57.2)$ & $76.9(46.2-95.0)$ \\
\hline - $x_{0}$ & 5 & 1 & 4 & 20 (п. а.) & 80 (n. а.) \\
\hline - XXX & $5^{*}$ & 1 & 4 & 20 (n. а.) & 80 (n. a.) \\
\hline - XXY & 1 & 1 & & 100 (n. а.) & \\
\hline - XYY & 1 & & 1 & & \\
\hline DiGeorge syndrome & 5 & & 5 & & $100(7.8-100)$ \\
\hline
\end{tabular}

- Table 3 US anomalies in fetuses with a positive cfDNA test result for T21, T18 or T13.

Fetuses receiving a detailed US in first trimester (CRL $\geq 45$ and $\leq 84 \mathrm{~mm})(\mathrm{n}=38)$

\begin{tabular}{|c|c|c|c|c|}
\hline & $\begin{array}{l}\text { Confirmed T21 } \\
n=25\end{array}$ & $\begin{array}{l}\text { Confirmed T18 } \\
\mathrm{n}=4\end{array}$ & $\begin{array}{l}\text { Confirmed T13 } \\
\mathrm{n}=2\end{array}$ & $\begin{array}{l}\text { False positive* } \\
\mathrm{n}=7\end{array}$ \\
\hline Any US anomaly & $23(88,5 \%)$ & $3(75 \%)$ & $2(100 \%)$ & 0 \\
\hline - NT $\geq 3.5 \mathrm{~mm}$ & $15(65.2 \%)$ & & 1 & \\
\hline - Absent nasal bone & $20(80.0 \%)$ & 0 & 1 & \\
\hline - TR & $12(48.0)$ & $2(50.0 \%)$ & & \\
\hline - Reverse flow DV & $12(48.0)$ & $1(25.0 \%)$ & 1 & \\
\hline - Heart & $6(24.0)$ & $2(50.0 \%)$ & 1 & \\
\hline - Other & $\begin{array}{l}\text { White spot LV } \\
\text { Holoprosencephaly }\end{array}$ & $\begin{array}{l}\text { Singular umbilical artery } \\
\text { Fetal tachycardia } \\
\text { Cleft lip and palate } \\
\text { Early fetal retardation }\end{array}$ & $\begin{array}{l}\text { Singular umbilical artery } \\
\text { Microcephaly } \\
\text { Polydactyly } \\
\text { Micrognathia } \\
\text { Lateral neck cyst }\end{array}$ & \\
\hline \multicolumn{5}{|c|}{ Fetuses receiving a detailed US in second trimester $(\geq 84 \mathrm{~mm})(n=17)$} \\
\hline & $\begin{array}{l}\text { Confirmed T21 } \\
n=13\end{array}$ & $\begin{array}{l}\mathrm{T} 18 \\
\mathrm{n}=1\end{array}$ & $\begin{array}{l}\mathrm{T} 13 \\
\mathrm{n}=0\end{array}$ & $\begin{array}{l}\text { False positive } \\
\mathrm{n}=3\end{array}$ \\
\hline Any US anomaly & $11(84.6 \%)$ & $1(100.0)$ & & 0 \\
\hline - Face and neck & $\begin{array}{l}9(69.2 \%) \\
\text { Nuchal oedema } \\
\text { Lateral neck cysts } \\
\text { Nasal bone hypoplasia }\end{array}$ & 0 & & \\
\hline - Heart & $\begin{array}{l}3(23.1 \%) \\
\operatorname{AVSD}(3)\end{array}$ & $\begin{array}{l}\text { Small muscular VSD } \\
\text { with left to right shunt } \\
\text { Small LV and large } \\
\text { intra-atrial aneurysm }\end{array}$ & & \\
\hline
\end{tabular}

- Other

White Spot in LV (5)

$\operatorname{TR}(1)$

Short femur (1)

Reverse flow in DV (3)

Mild hydronephrosis (1)

White spot liver (1)

ARSA (1)

ARSA: aberrant right subclavian artery; AVSD: atrioventricular septal defect; CRL: crown rump length; DV: ductus venosus; LV: left ventricle; NT: nuchal translucency; TR: tricuspid regurgitation; US: ultrasound; VSD: ventricular septal defect 
mester of pregnancy (GA 22+2; $23+0 ; 26+6$, respectively). All had nasal bone hypoplasia, two had white spots in the left ventricle and one had an atrioventricular septal defect (AVSD) ( $\vee$ Table 3). cfDNA test was performed following the detailed anomaly scan whereas the couples refrained from IPT. All children were delivered and T21 postnatally confirmed.

In 5 fetuses that were seen in the second trimester of pregnancy (GA 14+1-18+0), no anomalies were detected. The women had obtained a positive result in a cfDNA test ordered for primary screening and were referred to our practice for IPT (T21: $n=3$; T18: $n=1 ; T 13: n=1$ ). Two cases of T21 were confirmed by CVS and both pregnancies were terminated. In the other three cases, AC revealed a normal karyotype and the children were delivered.

\section{Case with a double positive cfDNA test}

One 30-year old patient was referred to our practice for amniocentesis at a GA $15+1$ due to a double positive cfDNA test result for T18 and triple $X$ syndrome. The fetus received a detailed US and appeared normal without any suspicious findings. Confirmatory genetic testing following AC revealed a normal karyotype and a healthy child was delivered.

\section{Cases with positive cfDNA test results for SCAs}

There were 18 fetuses that had a positive cfDNA test for a SCA. In all cases, cfDNA test was used as a primary screening method in the first trimester of pregnancy (GA $10+1$ to $13+5$ weeks). None of the fetuses displayed anomalies in detailed US scan in our practice (GA $12+2$ to $21+0$ weeks). Only 7 (38.9\%) of the parents opted for IPT (2 CVS, 5 AC). Postnatal testing results were available for 5 children and 6 had no confirmatory genetic testing at all. All children were delivered and 3 had a confirmed SCA (XXX, $X 0$ and $X X Y)$.

\section{Cases with a positive cfDNA test results for a microdeletion}

All 7 cases that had a cfDNA test predicting a 22q11.2 deletion were primary screening tests ordered by the patients' primary gynaecologists at a GA between $12+1$ and $12+7$ weeks. The patients were referred to our practice for IPT and/or further counselling. At a detailed US examination in our practice (GA $13+4$ to $15+2$ weeks), all fetuses appeared normal. Four couples opted for CVS with a negative result. Three decided against IPT, one of those had postnatal testing. There was no case with a confirmed DiGeorge syndrome.

\section{Number of positive cfDNA test per year}

The number of patients with a positive cfDNA test result in our practice strongly increased from one case in 2013 to 27 cases in 2019 ( $\triangleright$ Fig. 2). We encountered more than half of the cases $(56.8 \%)$ in the last two years (2018/2019). Furthermore, positive cfDNA test results for 22q11.2 deletion occurred only in 2018 and 2019.

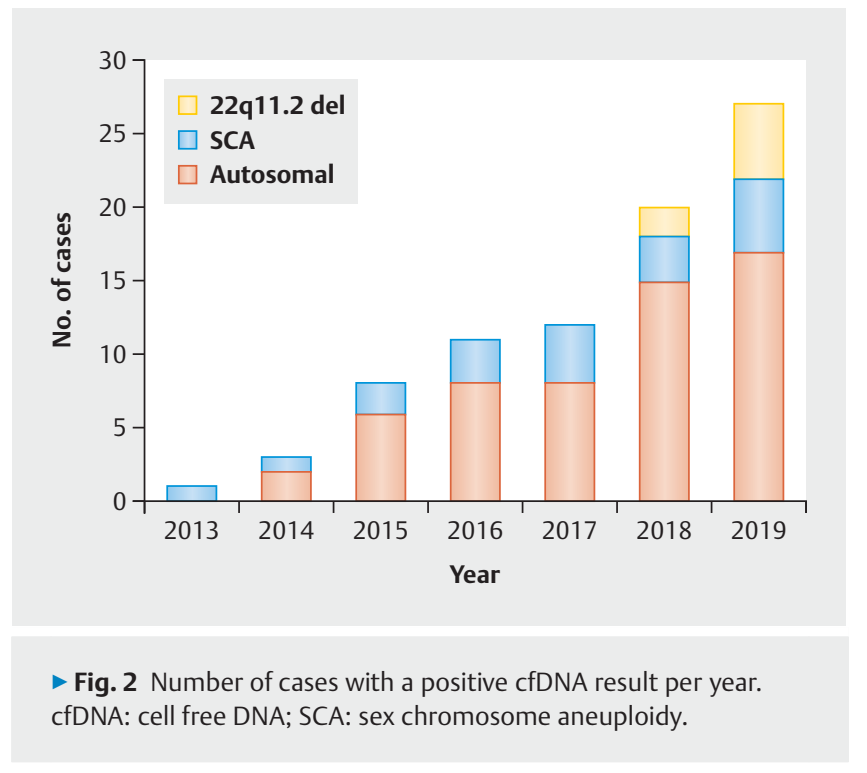

\section{Discussion}

This study retrospectively describes 81 cases with a cfDNA test predicting T21, 18 or 13 , a SCA or a $22 q 11.2$ microdeletion in a referral practice specialising in prenatal diagnosis in Germany. The PPV of cfDNA testing for T21 was $95 \%$. In contrast, only 55.6 and $28.6 \%$ of the cases with a positive cfDNA test for T18 and T13, respectively, were confirmed. About $75 \%$ of the test results predicting a SCA turned out to be false positive. No fetus was ultimately diagnosed with DiGeorge syndrome. Furthermore, our data reveals that adherence to the guideline recommendations on utilisation of cfDNA test by the primary obstetric providers tends to be low. Whereas national and international guidelines recommend cfDNA testing only following or in conjunction with a qualified US examination $[3,4]$, almost $2 / 3$ of the patients had not received a fetal anomaly scan before cfDNA test. Twenty-six patients had a cfDNA test positive for a SCA or a microdeletion, although testing for SCAs and microdeletions is not recommended due to insufficient clinical evidence $[3,4]$. Most of those occurred during the previous two years. Since we only included patients with a positive cfDNA test, we can merely speculate about the total number of cfDNA tests ordered for SCA or DiGeorge syndrome testing in our region.

The limitations of this study are its retrospective design that includes only patients with a positive cfDNA test result in our practice. Thus, we cannot evaluate the specificity, sensitivity or negative predictive value of cfDNA test. Although the cohort is rather large for a single referral centre the small sample allows only descriptive statistical analysis on the individual aneuploidies. Nevertheless, this study is based on a comprehensive database with known pregnancy outcome for all cases and covers the entire time period since cfDNA test is available in Germany. Moreover, it represents a population with a mixed aneuploidy risk typically seen in routine clinical practice.

It has been reported that the test quality of cfDNA tests in terms of specificity and sensitivity remains high in real-world conditions [5]. However, these parameters do not include prevalence. 
On the other hand, in the light of the excellent test quality of cfDNA test, the PPV, which largely depends on prevalence (and thus maternal age) of the tested condition, is often neglected [16]. Our study, which describes PPV estimates for cfDNA test in routine conditions in Germany, is in line with other real-world studies from the US, Sweden and China $[6,8,17,18]$ : The studies report PPVs for the individual autosomal aneuploidies ranging from T21: 83 to 94\%; T18: 64 to $76 \%$ and T13: 44 to $75 \%$ [6, 8, $17,18]$. Two studies report PPVs of approximately $40 \%$ for a combination of SCAs $[8,17]$. And three out of the four studies report only false positive cfDNA test results for 22q11.2 microdeletion $[6,8,17]$. Only the study of Petersen et al., which includes the largest cohort with 712 patients, reports a PPV of $21 \%$ for 22q11.2 microdeletion [18].

Similar to our study, these studies analyse fairly small cohorts, which are likely to differ in their age distribution, their risk profile and the indications for cfDNA test. This may account for the differing PPV-estimates and renders it impossible to make a direct comparison of the actual values. However, all studies clearly demonstrate that, in a typical population in routine practice, positive cfDNA test results must be carefully interpreted and appropriate counselling of the women concerned is of major importance.

A particularly worrying observation in this study is that almost two thirds of the patients did not receive a detailed US examination before cfDNA test. This might indicate that cfDNA testing is increasingly regarded as a replacement for a first trimester US anomaly screen and that the pregnant women are not aware that US can additionally detect anomalies unrelated to aneuploidies. On the other hand, about $90 \%$ of the fetuses with a confirmed autosomal aneuploidy displayed fetal anomalies amenable to first trimester US. In particular, fetuses with T13 and T18 are usually detectable by US in early pregnancy. Thus, the case with T18 with an inconspicuous US was rather unusual in our experience. Interestingly, a recent publication has shown that the time of intrauterine diagnosis of trisomies 21,13 and 18 has not changed in the past 10 years [19].

It has been shown that the implementation of cfDNA test as a screening method for T21 in a high-risk population decreases the rate of invasive diagnostics [20]. This positive effect might however be undermined by an indiscriminate usage of cfDNA test. Since cfDNA testing is a screening method, invasive prenatal testing is required to confirm a positive result. In our study, approximately half of the patients with a cfDNA test positive for a SCA or $22 q 11.2$ microdeletion underwent an invasive procedure - they would most probably not have done this if they had ordered the cfDNA test only for T21 without additional options and had obtained a negative result. Furthermore, about $25 \%$ of our study population was younger than 35 years old. Due to the low prevalence in women $<35$ years, the PPVs for T18 and T13 are predicted to be lower than 35 and $18 \%$, respectively [16]. Thus, broad usage of cfDNA test testing for T13 and T18 in low-risk pregnancies will be bound to result in false positive cases entailing unnecessary invasive procedures.

On the other hand - as described in several cases in our study cfDNA test can be a valuable option for parents where there is a high probability that their fetus has T21 due to typical US findings, but who want to have the child delivered and do not want to take the risk of IPT.

Although it is required by the German Genetic Diagnostics Act that gynaecologists must obtain a supplementary qualification for "subject-related genetic councelling" and are obliged to provide appropriate counselling to the patients [3], it is uncertain if the cfDNA test providers verify those requirements. In our experience, counselling prior to cfDNA-testing is often insufficient. Thus, a comprehensive education programme for primary obstetric providers and responsible counselling for pregnant women may help to increase sensible usage of cfDNA testing.

Primary gynaecologists must be aware that even a high specificity of cfDNA test for a certain aneuploidy of $>99 \%$ does not mean that less than $1 \%$ of the women undergoing the test will obtain a false positive result. Instead, they must consider the PPV and be aware that it largely depends on prevalence and thus age of the individual patient.

Adequate patient education about the various options of prenatal screening and their informative value is vital and decisions should not be driven by economic/financial aspects. Parents must understand that the cfDNA test cannot predict whether their child is healthy but can only exclude specific conditions. They should not be left alone to make their decision solely based on the information supplied by the cfDNA test providers (e.g. brochures, web pages), since these argue mainly in terms of specificity and sensitivity but neglect the PPV. Instead, they deserve the explanation that a positive test result has a certain probability to be false positive. And last but not least, parents should be encouraged to think about potential consequences of a positive test result, before actually undergoing the test.

\section{Conclusions}

This study demonstrates that in routine practice the PPVs for cfDNA testing for aneuploidies other than trisomy 21 are low. Often, cfDNA testing is performed without an accompanying ultrasound examination. Thus, utilisation of cfDNA testing in routine practice should be optimised.

\section{Acknowledgements}

The author wishes to thank Mandy Wegert for the dedicated management of the database, Dr. Silke Lange for statistical analysis and Dr. Sonja Hergeth for medical writing assistance.

\section{Conflict of Interest}

The authors declare that they have no conflict of interest.

\section{References}

[1] Gil MM, Accurti V, Santacruz B et al. Analysis of cell-free DNA in maternal blood in screening for aneuploidies: updated meta-analysis. Ultrasound Obstet Gynecol 2017; 50: 302-314. doi:10.1002/uog.17484

[2] Mackie FL, Hemming K, Allen S et al. The accuracy of cell-free fetal DNAbased non-invasive prenatal testing in singleton pregnancies: a systematic review and bivariate meta-analysis. BJOG 2017; 124: 32-46. doi:10.1111/1471-0528.14050 
[3] Schmid M, Klaritsch P, Arzt W et al. Cell-Free DNA Testing for Fetal Chromosomal Anomalies in clinical practice: Austrian-German-Swiss Recommendations for non-invasive prenatal tests (NIPT). Ultraschall Med 2015; 36: 507-510. doi:10.1055/s-0035-1553804

[4] Salomon LJ, Alfirevic Z, Audibert F et al. ISUOG updated consensus statement on the impact of cfDNA aneuploidy testing on screening policies and prenatal ultrasound practice. Ultrasound Obstet Gynecol 2017; 49: 815-816. doi:10.1002/uog. 17483

[5] Flock A, Tu NC, Ruland A et al. Non-invasive prenatal testing (NIPT): Europe's first multicenter post-market clinical follow-up study validating the quality in clinical routine. Arch Gynecol Obstet 2017; 296: 923928. doi:10.1007/s00404-017-4517-3

[6] Valderramos SG, Rao RR, Scibetta EW et al. Cell-free DNA screening in clinical practice: abnormal autosomal aneuploidy and microdeletion results. Am J Obstet Gynecol 2016; 215: 626.e1-626.e10. doi:10.1016/ j.ajog.2016.06.039

[7] Zhen L, Yang YD, Li Y] et al. The role of ultrasound in the choice between chorionic villus sampling and amniocentesis for patients with a positive NIPT result for trisomy 18/13. Prenat Diagn 2019; 39: 1155-1158. doi: $10.1002 / p d .5524$

[8] Zhou Q, Zhu ZP, Zhang B et al. Clinical features and pregnancy outcomes of women with abnormal cell-free fetal DNA test results. Ann Transl Med 2019; 7: 317. doi:10.21037/atm.2019.06.57

[9] Hartwig TS, Ambye L, Sorensen S et al. Discordant non-invasive prenatal testing (NIPT) - a systematic review. Prenat Diagn 2017; 37: 527-539. doi:10.1002/pd.5049

[10] Merz E, Eichhorn KH, von Kaisenberg C et al. [Updated quality requirements regarding secondary differentiated ultrasound examination in prenatal diagnostics (= DEGUM level II) in the period from $18+0$ to $21+6$ weeks of gestation]. Ultraschall Med 2012; 33: 593-596. doi: $10.1055 / \mathrm{s}-0032-1325500$
[11] Salomon L], Alfirevic Z, Berghella V et al. Practice guidelines for performance of the routine mid-trimester fetal ultrasound scan. Ultrasound Obstet Gynecol 2011; 37: 116-126. doi:10.1002/uog.8831

[12] Von Kaisenberg CS, Chaoui R, Häusler M et al. Quality Requirements for the early Fetal Ultrasound Assessment at 11-13+6 Weeks of Gestation (DEGUM Levels II and III). Ultraschall Med 2016; 37: 297-302

[13] Salomon L], Alfirevic Z, Bilardo CM et al. ISUOG practice guidelines: performance of first-trimester fetal ultrasound scan. Ultrasound Obstet Gynecol 2013; 41: 102-113. doi:10.1002/uog. 12342

[14] Ghi T, Sotiriadis A, Calda P et al. ISUOG Practice Guidelines: invasive procedures for prenatal diagnosis. Ultrasound Obstet Gynecol 2016; 48: 256-268. doi:10.1002/uog. 15945

[15] Kahler C, Gembruch U, Heling KS et al. [DEGUM guidelines for amniocentesis and chorionic villus sampling]. Ultraschall Med 2013; 34: 435440. doi:10.1055/s-0033-1335685

[16] Gießelmann K. Nichtinvasive Pränataltests: Risiko für Fehlinterpretation. Dtsch Arztebl 2020; 117: A-320/B-285/C-274

[17] Wang JC, Sahoo T, Schonberg $S$ et al. Discordant noninvasive prenatal testing and cytogenetic results: a study of 109 consecutive cases. Genet Med 2015; 17: 234-236. doi:10.1038/gim.2014.92

[18] Petersen AK, Cheung SW, Smith JL et al. Positive predictive value estimates for cell-free noninvasive prenatal screening from data of a large referral genetic diagnostic laboratory. Am J Obstet Gynecol 2017; 217 : 691.e1-691.e6. doi:10.1016/j.ajog.2017.10.005

[19] Prodan N, Hoopmann M, Abele $\mathrm{H}$ et al. Changes in the Detection and Management of Foetal Trisomies over Time. Geburtshilfe Frauenheilkd 2018; 78: 853-858. doi:10.1055/a-0648-5374

[20] Bjerregaard L, Stenbakken AB, Andersen CS et al. The rate of invasive testing for trisomy 21 is reduced after implementation of NIPT. Dan Med J 2017; 64: A5359 